\title{
LIVING IN FOSTER CARE AND IN A CHILDREN'S HOME: VOICES OF CHILDREN AND THEIR CAREGIVERS
}

\section{Nevashnee Perumal, Madhu Kasiram}

\section{INTRODUCTION}

Foster care is clearly seen as the preferred option in alternate care of the vulnerable child in South Africa and internationally (Kiraly, 2001; Long, 2007; McKay, 2002; Morei, 2002). The Children's Act 38/2005 clearly prioritizes a foster care placement over a child and youth care centre of which a Children's Home is a part (Section 46(1)(a) - Children's Act 38/2005 (http://www.acts.co.za). Given the steady decline in traditional family living due to amongst other factors HIV/AIDS, poverty and unemployment in South Africa, the dominant view of family care being prioritized may not always be feasible. This paper provides researched evidence of lived experiences in both alternative care placements to deepen understanding of best practice options for alternate care planning and management.

The objectives of the research study were:

- to explore children's experiences of foster care and the Children's Home placement.

- to explore experiences and challenges of foster parents and caregivers in Children's Homes in caring for vulnerable children.

\section{RESEARCH METHODOLOGY}

The study used a multi-methods approach employing qualitative methodologies to glean a comprehensive picture of the topic (De Vos, Strydom, Fouche \& Delport, 2002). To this end both exploratory and descriptive designs using semi-structured in depth interviews with the child participants and focus group discussions with caregivers were jointly used to obtain rich descriptions to contribute to understanding each placement from different vantage points. Using multiple samples and methods increased the trustworthiness of the study, and contributed to triangulation to authenticate research findings (Lincoln \& Guba, 1985).

Both the in depth interviews as well as the focus group discussions were guided by similar themes that were linked to the objectives of the study.

A purposive sampling strategy was used as there were clear criteria for the selection of participants, viz. that the children had to have experience of living in both settings from 2003 to 2006 for a minimum of three months; and caregivers were simply the legal guardians of these children. The locale for the study was a child and family welfare agency in KwaZulu-Natal to which the authors had access. The agency serviced all population groups from a variety of geographical districts, thus being fairly representative of the general population of families receiving services at all agencies in the country. The final sample consisted of 13 children. Two focus groups were conducted, one with foster parents (group of 8) and one with child care workers (group of 5) from the Children's Homes.

Data was analyzed by categorizing and establishing meaning units (Punch, 2000) of the rich descriptions relating to both living options from both sample groups.

The study was guided by the following key assumptions and theoretical frames of reference:

The voices of children in alternative care settings may be overlooked when acting in their best interests in spite of intention to do so because of a powerful and complicated context. This 
assumption has relevance for both ecological and structural social work perspectives. For structural social work, oppressive, contextual and political forces may mitigate against families caring for their vulnerable children (Mullaly, 1993) and from an ecological perspective, along with a variety of microsystemic and mesosystemic influences, impoverishment has a direct bearing on a family's ability to care adequately for its children.

A further assumption was that although both foster families and Children's Homes may be inadequately equipped to deal with the challenges presented by children in need of care, Children's Homes may be better resourced by the state than foster families to cope with vulnerable children, challenging the dominant view of families always providing the best environment for caring for vulnerable children (Perumal \& Kasiram, 2008). This view is held because many families are simply unable to uphold their "inherent" ability to care effectively as they are ravaged by such like as HIV/AIDS, poverty and violence (Hochfeld, 2007). Again both ecological and structural theories can be used to explain these challenges where some attempt at redress unbalances the delicate juxtaposition of societal versus family pressures and responsibilities.

\section{RESULTS AND DISCUSSION}

Results and discussion will be presented thematically in accord with the objectives mentioned earlier.

\section{THE SAMPLE}

Thirteen children consented to participate in the study, five of which had moved through multiple foster homes.

Seven children's homes agreed to participate in the focus group discussions which eventually comprised five members.

Of the 13 child participants representing 11 foster homes, four foster parents eventually attended the group discussion.

Clearly the sample across all three levels is small but this did not detract from gleaning rich, qualitative descriptions from respondents (De Vos et al., 2002).

\section{NEGATIVE EXPERIENCES OF CHILDREN PERTAINED TO DECISIONS ABOUT THEIR FUTURE}

All children (bar one) were completely or partially unaware of the reasons for and of the legal processes surrounding their removals, exemplified in the following statements by respondents:

“social workers took me away from home, (my) mother wasn't there, I didn't ask where I was going (child aged 10);

aunty $S$ packed my bags (and) said we are going to town but took me to the Homes. No one asked if I wanted to go...(child aged 11)."

Caregivers responded similarly, not only verifying that the children were largely unaware of the reasons for and processes involved in their removal but also that they themselves lacked knowledge on how or why these children were in their care! Clearly communication with significant stake holders viz. social worker, child and caregiver is lacking, suggesting immediate change of the status quo and monitoring to ensure that transparency and improved communication becomes an important key ingredient of alternate care planning and practice (Sheafor, Horejsi \& Horejsi, 1997). 
Children were also found to be uncertain of the length of time in each placement, a curious phenomenon given their enthusiasm to plan and dream about the future, but without time lines. However, children clearly remembered each placement and what happened in between each court order and subsequent placement.

The assumption that the needs/voices of children may be overlooked when acting in their best interests was confirmed. The authors agree with Van Niekerk (2007) and Fowler (2003) who call for increased child participation since professionals appear to continue to work from a position of authority that is based on hard earned years of experience and training. This experience and training may prevent professionals from realizing that young people may actually be the best experts on childhood and youth. It is essential to complement professionals' voices with children's voices in acting in children's best interests.

\section{POSITIVE EXPERIENCES OF LIVING IN FOSTER CARE AND IN A CHILDREN'S HOME}

It was found that in both placements, positive experiences for children were: being provided for materially and enjoying social outings and celebrations. These are in accord with Maslow's hierarchy of needs, representing both basic and higher order need but with both being considered equally significant. Belonging has to do with a sense of relatedness, reflective of attachment, respect and love, core ingredients of healthy family living. Interestingly, although children valued nurturing relationships with foster families and child caregivers, they expressed a desperate longing for their families of origin stating:

“...I was always depressed... used to wait for my mother to visit (child in a children's home)

There's nothing nice here...want to be with my mother (child in foster care)."

It is possible that these statements reflect love and care from a family of origin being superior to the experience in either the foster home or Children's Home and suggests that even though the family of origin may experience grave problems, it is still much valued (Maluccio, Fein \& Olmstead, 1986).

Ecological theory accommodates simultaneous care and development of the biological family whilst the child is temporarily away from home, thereby recognizing parents as partners in family preservation. However, the study found that this ideal is far removed from reality where children are not always consulted about their future care, and that they wait far too long before any reconstruction with families of origin takes place. Given, the country's structural deficiencies, it is questionable whether any reconstruction is possible in a context of poverty and loss of parents to AIDS.

In South Africa, the Department of Welfare (Developmental Assessment of Children, Youth and Families, 2000) has attempted to address this concern for reconstruction by proposing a programme called the Developmental Assessment of Children, Youth and Families. Moodley (2006) is of the view that social workers appear to be inadequately trained to use this tool, given gaps in services surrounding reconstruction. Further, although ecologically, theoretical provision is made to address imbalance across concentric spheres of interrelationship in child and family life, structural constraints prevent the ideal from being practised.

In the Children's Home, sport, rewards linked to programmes and relationships with other children were valued. The expressed need for belonging, relatedness, love and care is fulfilled by peers, hence relationships with other children being fondly recalled: 
"We made friends there...

We bake (for a) birthday and celebrate at the poolside."

In Children's Homes, results point to peer support being considered more important than nurturing relationships with caregivers, a finding supported by Brandon, Schofield and Trinder (1998). A Children's Home is not mandated by legislation to provide the "human element" of nurturing a child. Rather its key function is to provide care for more than six children in accordance with a residential care programme suited to children in a specific facility (Children's Amendment Bill [B19-2006] http:www.socdev.gov.za/media/2005/april/budget\%20vote/families.htm). De Vos (1997) confirms that childcare staff play a critical role in assisting a child with his/her development to facilitate reintegration into society. This must surely incorporate both care and nurturing since unsupervised, children's future may be ominous with poor decision making and negative peer influence. Structural deficiencies such as these together with employing an ecological perspective that recognizes all interacting influences must clearly be adopted to attend to both care and nurture of the vulnerable child.

\section{NEGATIVE EXPERIENCES OF LIVING IN FOSTER CARE AND IN A CHILDREN'S HOME}

It was found that the physical and emotional wellbeing of children was compromised in both placements.

Foster parents complained of hardships with accessing the foster care grant and the children, of having to do chores. According to Jacobs, Shung-King and Smith (2005), there is an increasing number of poverty stricken families who care for orphaned children and who rely on foster care grants as their sole source of income. This situation exists because instead of the state providing a Basic Income Grant (BIG) for all or extending the child support grant, it has implemented systems such as the South African Social Security Agency (SASSA). One of SASSA's functions is to speed up the foster care grant applications); the other is to root out social security fraudsters (unauthored, http://www.services.gov.za), who include poverty stricken grandmothers taking care of multigenerational families. Therefore foster parents who may be grandmothers will be prosecuted if reported to SASSA and their grants terminated, placing immeasurable strain and hardship on the family and compromised care of the child. Thus optimum care within a family setting is impossible, without supportive infrastructure. Again we see how an ecological framework must be complemented by a structural approach for good practice to prevail.

In the Children's Home, a lack of trained staff, negative peer influence and only the fittest surviving the harsh climate of impersonal care, were expressed concerns. Thus, although Children's Homes are financially better resourced than foster families, there is a distinct weak human resource component that exists in Children's Homes. According to De Vos (1997) and Knuttson (1997) historically, Children's Homes were established to care for orphaned, needy and child victims of epidemic outbreaks. Presently, children requiring alternative care also come from dysfunctional families and may require emotional support, not always available in the Children's Home.

The study found that the support of significant adult caregivers in the Children's Home was absent. This results in children depending on their peers instead of adults. According to Brandon et al. (1998) children depend on their peers throughout their development but would need consultation and support from significant adult caregivers to make the right choices in 
life. It is important for young people to be able to consult with adults who they trust. An urgent need clearly exists for adult caregivers to be physically and emotionally available through therapeutic programmes or infrastructural support for this to happen.

Child participants preferred to live with their families of origin irrespective of their families' circumstances or inability to keep them safe. This was in spite of foster placements having broken down. Thus, the centrality of the family (which supports the dominant ideology that family care should supersede all other forms of care) cannot be negated (Maluccio et al., 1986). In this regard, Moodley (2006) suggests that family preservation needs to be given priority to avoid removal and entrench belonging. Family preservation programmes could emphasise parenting skills as part of an early intervention strategy to empower and capacitate families of origin, leading to fewer children being removed and placed in alternative care. From an ecological perspective a child's separation from their family of origin results in relationships being fractured at the micro level of functioning. These suggestions are framed by both an ecological underpinning (micro level support) and macro level infrastructural attention to redress imbalances (Sewpaul, 2005) in family oriented care.

Children's critique of professional services was of social workers providing for visits to the family of origin over holidays and securing host and foster families. Curiously, psycho social support and therapeutic services were not mentioned. According to Sheafor et al. (1997) social workers should help individuals and families to introspect, modify behaviours and cope with problems. In South Africa, many challenges facing families are attributable to its historical past. Social workers appear to be ill equipped and under resourced to meet these challenges (Moodley, 2006) hence the "band aid" nature of services mentioned by child participants. The authors agree with Sewpaul (2005) and Sheafor et al. (1997) that effective social work services need to be guided by a structural social justice approach in view of the country's legacy of oppressive practices that advantaged selected groups only.

\section{EXPERIENCES AND CHALLENGES OF CAREGIVERS}

A striking finding was that the reasons given by the caregivers for caring for vulnerable children were in most instances contradictory to the child participants' experiences of living in both placements. The caregivers' reasons for caring for vulnerable children were itemised as wanting to understand and help vulnerable children (childcare workers) and meet their emotional and physical needs; and sense of duty/obligation to care for kith and kin (foster parents). Clearly, based on child participants' views, a disparity existed between verbalised intention and actual care. It is necessary for the voices of children to be magnified but balanced with social work support in determining their best interests (Long, 2007; Van Niekerk, 2007) to bridge this gap. This constitutes an empowerment strategy to promote better fit between children and their environments (ecological approach) and from a structural perspective, may diminish dominant and oppressive adult influences that may indeed harm vulnerable children.

Positive caregiver experiences were related to pride and joy when children in their care excelled academically, in sport or showed initiative in community projects. Foster parents also mentioned an inner satisfaction when children in their care acknowledged their care and affection, showed respect and fitted into their family. So, this sense of belonging emerges again as a core ingredient, peculiar to families as opposed to Children's Homes (Draft National Family Policy, 2005). McKay (1994) refers to children needing sensitive, individual attention, familiar surroundings and intellectual stimulation. Although none of these may be available through living in a Children's Home, it is equally true that a depleted, deprived family 
environment (where parents have perhaps died of AIDS) cannot hope to provide for these needs, reiterating the need for redress using a structural-ecological framework.

Caregivers expressed concern about inadequate reunification, not coping with problematic behaviour, inadequate support for children with disabilities in foster care and children not fitting into the programme/foster family. These challenges, although rooted in structural deficiencies such as inadequate support to foster families and Children's Homes, also have roots in the ecological framework such as the child's sense of belonging being eroded by poor parenting.

Although Children's Homes managed these challenges in some measure, foster families were more creative and resourceful. Perhaps it is the bureaucracy in Children's Homes that contributes to lack of creativity and timeous, corrective action. These spontaneous, creative methods in coping and caring need to be affirmed and harnessed by social workers for the purpose of replication in both foster families as well as Children's Homes. After all, clients are expert of their own lives and given the opportunity may arrive at their own self healing with excellent effect.

\section{CONCLUSION AND RECOMMENDATIONS}

In hearing the voices of children and their caregivers, it appeared that although Children's Homes were financially better off than foster families to care for vulnerable children, they were not better resourced. Both placements lacked infrastructural support, therefore being unable to adequately respond to the needs of vulnerable children. A key finding was the need for children's voices to be heard when acting in their best interests, captured in the following words of one child participant:

Children can't always make decisions for themselves but should be given the opportunity to participate in decisions made for them (C-16).

The recommendations that follow are accommodated within ecological and structural frames of reference and are derived both from a critical appraisal of the findings and from suggestions made by participants.

Children as partners: Children need to be embraced as "partners" through direct engagement, involving them in decisions about choice of therapeutic interventions and using child friendly resource materials. Pre-placement preparation will also afford them a voice and respect of their views. A further recommendation is for the child to be taken to court prior to a Children's Court Inquiry, so that the child is not intimidated during the actual finalisation of the Children's Court Inquiry. By removing the discomfort of an unfamiliar environment, a child's participation may be enhanced.

Minimal standards for child protection: It is recommended that national, standardized, minimum child protection procedures be documented and followed with rigour to ensure that due regard be afforded children's care, countrywide.

One-stop service centres: Readily accessible, one-stop service resources for caregivers and children are needed. Although this concept exists currently, centres are under- resourced, appear to operate without national guidelines and lack co-ordinated, multi-professional services, compromising holistic care of the child and family. 
Sense of belonging: It is recommended that caregivers make use of novel ways to foster a sense of belonging in the different placements e.g. honing in to a visually impaired child's reading strengths and getting that child to "read off" with his visually able peers.

Education, support and training: Caregivers need to be formally educated and trained since caring for children is a highly skilled function. Training should include dealing with the emotional aspects of caring for children, trust building and legislation pertaining to child care. Such training must be regular and continuous and supported with literature and manuals for ease of reference. If caregivers are so trained, they may demand a salary commensurate with their training and ultimately enjoy a better standard of living together with being better valued. The same sentiment on education and training exists for social workers whose services were found to be lacking in this study.

Care for carers: In South Africa, caregivers as well as social workers attend to children who have been abused, may be terminally ill or who have HIV/AIDS and this is traumatizing. Trauma debriefing and other self care strategies should be built into respite care programmes for caregivers and social workers alike.

Social work services: It is recommended that minimum standards for social workers in Child Welfare be developed and regulated by a national body and recorded in a manual or handbook. Regulation should replace current top-down approaches used in supervision of social workers with a lateral, strengths-based approach of co-vision. Social workers may then be stroked and supported by managers leading from a step behind as opposed to managers racing ahead with all the answers. Co-vision empowers newer social workers with confidence as it would children as partners in revolutionising child care practice.

Networking is recommended among agency social workers, caregivers, children and families of origin in order to ensure reunification and permanency planning e.g. by holding quarterly case reviews.

It is further recommended that all interventions be time-limited in order for children not to remain in alternative care indefinitely.

Families of origin: Because of children's preference to live with their families of origin, it is recommended that a structurally balanced national family preservation programme be formulated. This programme should contract with parents from the outset ensuring their commitment to the programme. Further, the programme needs to be time-limited so that families are capacitated to resume responsibility for their children within a specified time. The programme should embody direct counselling services and parenting skills on the micro level, group support from other parents on the meso level and community awareness on the macro level. Another key ingredient of the programme could be aimed at restoring the financial status of families of origin by providing a Basic Income Grant (BIG) to all poverty stricken families and/or extending the Child Support Grant (CSG). This financial aid must be balanced with finance management education to better manage financial stress.

Support Groups: Since caregivers were not adequately supported by social workers and/or management structures, it is recommended that support groups be formed with foster parents, with childcare workers and with social workers. These groups would bring people together for the purposes of sharing experiences, challenges and best practices. This could also promote teamwork to strengthen existing human resources and minimize manipulation by children. Teamwork at agency level may be managed by holding daily eight minute morning meetings 
(as is done at one of the Child Welfare Societies in KwaZulu-Natal) to allow all team members to touch base and speak with one voice on issues pertaining to children.

\section{Future research focus:}

- similar but larger studies throughout the province and/or in other provinces to improve generalization;

- other related areas including factors contributing to family disintegration, the role of children in families and formulating a national family preservation programme;

- participatory action research to capacitate families of origin in assuming responsibility for their children;

- and a comparative study between the Child Care Act74/1983 and the Children's Act $38 / 2005$ with specific reference to the impact of changes in legislation on vulnerable children as this could directly guide best practice.

\section{REFERENCES}

BRANDON, M., SCHOFIELD, G. \& TRINDER, L 1998. Social work with children. London: MacMillan Press.

CHILDREN'S ACT 38/2005. Available: http://www.acts.co.za. [Accessed: 03/04/2007].

CHILDREN'S AMENDMENT BILL [B19-2006]. Available: http://www.info.gov.za/gazette/ bills/2006/b19-06.pdf. [Accessed: 03/04/2007].

CHILD CARE ACT 74/1983. Available: http://www.acts.co.za. [Accessed: 03/04/2007].

DEVELOPMENTAL ASSESSMENT OF CHILDREN, YOUTH AND FAMILIES. 2000. Master Trainers Guide. Republic of South Africa.

DE VOS, M.S. 1997. The social orientation of a child in a children's home. Social Work Practice, 97(2):15-20.

DE VOS, A.S., STRYDOM, H., FOUCHÉ, C.B. \& DELPORT, C.S.L. 2002. Research at Grass Roots: for the social sciences and human sciences professions $\left(2^{\text {nd }}\right.$ ed). Pretoria: Van Schaik Publishers.

DRAFT NATIONAL FAMILY POLICY 2005. Fact sheet: processes and programmes that enhance family life. Available: http://www.socdev.gov.za/media/2005/april/budget\%20vote/ families.htm. [Accessed: 21/05/2007].

FOWLER, J. 2003. A practitioner's tool for child protection and the assessment of parents. London: Jessica Kingsley Publishers Ltd.

HOCHFELD, T. 2007. Missed opportunities: conservative discourses in the draft National Family Policy of South Africa. International Social Work, 50(1):79-91.

JACOBS, M., SHUNG-KING, M. \& SMITH, C. (eds) 2005. South African Child Gauge 2005. Children's Institute, University of Cape Town, Cape Town.

KIRALY, M. 2001. Residential child care staff selection: choose with care. USA: Haworth Press Inc.

KNUTSSON, K.E. 1997. Children: noble causes or worthy citizens $\left(1^{\text {st }}\right.$ ed). England: Ashgate Publishing Limited. 
LINCOLN, Y.S. \& GUBA, E.G. 1985. Naturalistic inquiry. Newbury Park: Sage Publications.

LONG, S. 2007. Children at the Centre: a guide to supporting community groups caring for vulnerable children: London: Save the Children.

MALUCCIO, A.N., FEIN, E. \& OLMSTEAD, K.A. 1986. Permanency planning for children-concepts and methods. London: Tavistock Publications.

McKAY, A. 1994. No love nor money: institutional child care in South Africa. Critical Health, 46:79-82.

McKAY, P. 2002. Orphans - the case for community care: invest in families for the sake of the children. Children First, 6(42):26-28.

MOODLEY, R. 2006. The challenges confronting social workers in meeting the objectives of permanency planning at children's homes, in the magisterial district of Durban. Durban: University of KwaZulu-Natal. (Submitted in part fulfilment of the requirements for the degree of MA (Social Work))

MOREI, N. 2002. The right to family life: courts start to see household diversity. Children First, 6(45):7-10.

MULLALY, R. 1993. Structural social work: ideology, theory and practice. Toronto: McClelland and Stewart Inc.

PERUMAL, N. \& KASIRAM, M. 2008. Children's homes and foster care: challenging dominant discourses in South African social work practice. Social Work/Maatskaplike Werk, 44(2):159-169.

PUNCH, F.K. 2000. Developing effective research proposals. London: Sage Publications.

SEWPAUL, V. 2005. A structural social justice approach to family policy. Social Work/Maatskaplike Werk, 41(4):311-323.

SHEAFOR, B.W., HOREJSI, C.R. \& HOREJSI, G.A. 1997. Techniques and guidelines for social work practice (4th ed). Boston: Allyn and Bacon.

VAN NIEKERK, J. 2007. Child participation - the Challenges for child protection workers.

The International Society for the Prevention of Child Abuse and Neglect - Special Report, 1:10-11.

\section{WEB SITES (UNAUTHORED)}

Unauthored, Family support services. Available: http://www.services.gov.za. [Accessed: 21/05/2007]

Ms Nevashnee Perumal, social worker, Pietermaritzburg Child and Family Welfare Society, Pietermaritzburg, KwaZulu-Natal, South Africa.

Professor Madhu Kasiram, School of Social Work and Community Development, UKZN-Howard College Campus, KwaZulu-Natal, South Africa. 